\title{
Pengaruh Pemberian Pupuk NPK Mutiara Terhadap Pertumbuhan Anakan Jernang (Daemonorops draco) Pada Tanah Podsolik Merah Kuning
}

\author{
M.Kurniawan Candra \\ Fakultas Pertanian Universitas Kapuas Sintang \\ Email : candra_kurniawanmuhamad@gmail.com
}

\begin{abstract}
Abstrak: Penelitian ini bertujuan untuk mengetahui pengaruh pemberian pupuk NPK Mutiara dan dosis yang terbaik dalam mempengaruhi pertumbuhan anakan Jernang (Daemonorops draco) pada tanah Podsolik Merah Kuning. Hasil penelitian ini diharapkan dapat menambah ilmu dan pengetahuan terutama mengenai pengaruh pemberian pupuk NPK Mutiara terhadap pertumbuhan anakan Jernang pada tanah Podsolik Merah Kuning dan dapat dijadikan sebagai salah satu acuan dalam upaya pembibitan anakan Jernang. Metode yang digunakan dalam penelitian ini adalah pola dasar Rancangan Acak Lengkap (RAL) dengan perlakuan tunggal adalah pupuk NPK Mutiara yang terdiri dari 4 taraf perlakuan yaitu : Tanpa pupuk NPK Mutiara $\left(\mathrm{N}_{0}\right)$, NPK Mutiara 40 gram per anakan $\left(\mathrm{N}_{1}\right)$, NPK Mutiara 50 gram per anakan $\left(\mathrm{N}_{2}\right)$ dan NPK Mutiara 60 gram per anakan $\left(\mathrm{N}_{3}\right)$. Rancangan ini dipilih karena anakan Jernang, lingkungan tempat tumbuh dan alat yang digunakan dalam penelitian relatif homogen (seragam). Hasil penelitian diketahui bahwa Pemberian pupuk NPK Mutiara berpengaruh sangat signifikan terhadap pertambahan tinggi dan pertambahan jumlah daun anakan Jernang pada tanah Podsolik Merah Kuning. Perlakuan pemberian pupuk NPK Mutiara dengan dosis 50 gram per anakan $\left(\mathrm{N}_{2}\right)$ adalah yang terbaik dibandingkan dengan perlakuan lainnya, untuk meningkatkan pertambahan tinggi (rerata $5,50 \mathrm{~cm}$ ) dan pertambahan jumlah daun anakan Jernang (rerata 3,33 helai). Perlu dilakukan kajian yang lebih mendalam untuk melihat pengaruh pemberian pupuk NPK Mutiara terhadap pertumbuhan anakan Jernang yaitu dengan cara menambah lamanya waktu penelitian, sehingga didapatkan kesimpulan yang menyeluruh dan utuh.
\end{abstract}

Kata Kunci: Pupuk NPK Mutiara, Pertumbuhan Tinggi dan Jumlah Daun, Tanah Podsolik Merah Kuning

\section{PENDAHULUAN}

Masyarakat sekitar hutan sudah sejak lama menggantungkan hidupnya dari berbagai hasil hutan, baik hasil hutan berupa kayu maupun non kayu. Hasil hutan berupa kayu dimanfaatkan oleh masyarakat untuk berbagai keperluan antara lain sebagai bahan konstruksi bangunan, untuk membuat pintu, jendela, kusen, lemari, kursi, meja dan lain sebagainya. Pohon Jernang atau yang paling dikenal dengan nama Jernang adalah salah satu jenis hasil hutan non kayu yang terdapat pada hutan tropis Indonesia. Jernang ini secara umum sangat dikenali oleh masyarakat sekitar maupun dalam kawasan hutan, karena dapat menghasilkan getah yang digunakan oleh masyarakat untuk berbagai keperluan. Jernang dapat digunakan sebagai bahan kerajinan dan obat-obatan bagi masyarakat setempat.

Setiap upaya budidaya tentu terdapat banyak hambatan, antara lain ketersediaan bibit yang siap tanam, media tanam dan dosis pupuk yang akan diberikan. Di Kalimantan Barat khususnya di Kabupaten Sintang, media tanam yang paling dominan adalah tanah Podsolik Merah
Kuning (PMK). Tanah ini dikenal dengan tanah yang miskin unsur hara, sehingga dalam upaya budidaya mutlak memerlukan pupuk untuk menambah unsur hara agar tanaman dapat tumbuh dan berkembang dengan baik sesuai yang diharapkan. Tersedianya bibit yang baik dan sehat sangat ditentukan oleh upaya yang dilakukan.

\section{METODOLOGI PENELITIAN}

\section{Rancangan Penelitian}

Metode yang digunakan dalam penelitian ini adalah pola dasar Rancangan Acak Lengkap (RAL) dengan perlakuan tunggal adalah pupuk NPK Mutiara yang terdiri dari 4 taraf perlakuan yaitu : Tanpa pupuk NPK Mutiara $\left(\mathrm{N}_{0}\right)$, NPK Mutiara 40 gram per anakan $\left(\mathrm{N}_{1}\right)$, NPK Mutiara 50 gram per anakan $\left(\mathrm{N}_{2}\right)$ dan NPK Mutiara 60 gram per anakan $\left(\mathrm{N}_{3}\right)$. Rancangan ini dipilih karena anakan Jernang, lingkungan tempat tumbuh dan alat yang digunakan dalam penelitian relatif homogen (seragam). Ruang lingkup penelitian terdiri dari dua variabel yaitu variabel bebas dan variabel terikat. Variabel bebas adalah dosis pupuk NPK Mutiara yang terdiri dari 4 taraf yaitu : Kontrol 
$\left(\mathrm{N}_{0}\right)$, NPK Mutiara 40 gram per anakan $\left(\mathrm{N}_{1}\right)$, NPK Mutiara 50 gram per anakan $\left(\mathrm{N}_{2}\right)$ dan NPK Mutiara 60 gram per anakan $\left(\mathrm{N}_{3}\right)$, sedangkan variabel terikat pada penelitian ini adalah pertumbuhan anakan Jernang yang meliputi pertambahan tinggi anakan $(\mathrm{cm})$ dan pertambahan jumlah daun (helai).

Hipotesis dalam penelitian ini adalah :

$\mathrm{H}_{0} \quad$ : Diduga pemberian pupuk NPK Mutiara tidak memberikan pengaruh yang signifikan terhadap pertumbuhan anakan Jernang pada tanah PMK.

$\mathrm{H}_{1}$ : Diduga pemberian pupuk NPK Mutiara memberikan pengaruh yang signifikan terhadap pertumbuhan anakan Jernang pada tanah PMK.

\section{Populasi dan Sampel}

Jumlah populasi dalam penelitian ini adalah 4 taraf perlakuan dosis pupuk NPK Mutiara, masingmasing perlakuan diulang sebanyak 6 kali dan setiap ulangan terdapat 4 anakan, sehingga terdapat 96 anakan Jernang. Sampel dalam penelitian ini diambil sebanyak 2 anakan setiap ulangan sehingga anakan Jernang yang diamati sebanyak 4 x 6 ulangan $\mathrm{x} 2$ bibit $=48$ anakan.

\section{Analisis Data}

Data hasil penelitian dianalisis sesuai dengan rancangan penelitian yang digunakan. Menurut Hanafiah (2008:25), model statistika untuk percobaan tunggal dengan menggunakan rancangan dasar RAL, adalah sebagai berikut:

$\mathbf{Y}_{\mathrm{ij}}=\mathbf{m}+\mathbf{t i}+\mathbf{e i j} ;$

di mana :

$$
\begin{aligned}
\mathrm{Y}_{\mathrm{ij}} & =\text { Nilai pengamatan } \\
\mathrm{m} & =\text { Nilai rerata harapan } \\
\mathrm{t} & =\text { Pengaruh perlakuan } \\
\mathrm{e}_{\mathrm{ij}} & =\text { Pengaruh galat }
\end{aligned}
$$

\section{HASIL DAN PEMBAHASAN}

\section{Hasil Penelitian}

\section{Pertambahan Tinggi Anakan}

Pertambahan tinggi anakan merupakan hasil perhitungan yang didapatkan dengan cara mengurangi tinggi anakan pada akhir penelitian PIPER No. 31 Volume 16 Oktober 2020 dengan tinggi anakan pada awal penelitian. Data hasil rerata pertambahan tinggi anakan Jernang pada tanah Podsolik Merah Kuning selama penelitian dapat dilihat pada tabel 4.1. Dari tabel 4.1, selanjutnya dilakukan analisis sidik ragam. Hasil analisis sidik ragam pengaruh pemberian pupuk NPK Mutiara terhadap pertambahan tinggi anakan Jernang pada tanah Podsolik Merah Kuning.

Berdasarkan hasil analisis sidik ragam pada tabel 4.2 tersebut, diketahui bahwa pemberian pupuk NPK Mutiara memberikan pengaruh yang sangat signifikan terhadap pertambahan tinggi anakan Jernang pada tanah Podsolik Merah Kuning. Untuk mengetahui perlakuan yang terbaik dalam mempengaruhi pertambahan tinggi anakan Jernang, maka dilakukan pengujian terhadap rerata perbedaan masing-masing perlakuan dengan menggunakan Uji Beda Nyata Terkecil (BNT) pada taraf nyata $5 \%$ dan $1 \%$. Hasil Uji BNT perbedaan masing-masing perlakuan pupuk NPK Mutiara terhadap pertambahan tinggi anakan Jernang pada tanah Podsolik Merah Kuning.

Hasil uji BNT pada tabel 4.3, diketahui bahwa pemberian pupuk NPK Mutiara dengan dosis 50 gram per anakan (N2), merupakan perlakuan terbaik untuk meningkatkan pertambahan tinggi anakan Jernang. Hal ini terlihat dengan jelas bahwa $\mathrm{N} 2$ berbeda sangat signifikan dibandingkan dengan N3 (pupuk NPK Mutiara 60 gram per anakan), dengan N1 (pupuk NPK Mutiara 40 gram per anakan) dan dengan N0 (tanpa pupuk NPK Mutiara).

\section{Pertambahan Jumlah Pelepah Daun Anakan}

Pertambahan jumlah daun anakan merupakan hasil perhitungan, yang didapatkan dengan cara mengurangi jumlah daun anakan pada akhir penelitian dengan jumlah daun anakan pada awal penelitian. Data hasil rerata pertambahan jumlah daun anakan Jernang pada tanah Podsolik Merah Kuning selama penelitian dapat dilihat pada tabel 4.4. Dari tabel 4.4, selanjutnya dilakukan analisis sidik ragam.

Berdasarkan hasil analisis sidik ragam pada tabel 4.5 tersebut, diketahui bahwa pemberian pupuk NPK Mutiara memberikan pengaruh yang sangat signifikan terhadap pertambahan jumlah daun anakan Jernang pada tanah Podsolik Merah Kuning. Untuk mengetahui perlakuan yang terbaik dalam mempengaruhi pertambahan jumlah daun anakan Jernang, maka dilakukan pengujian terhadap rerata perbedaan masing-masing perlakuan dengan menggunakan Uji Beda Nyata Terkecil (BNT) pada taraf nyata 5\% dan $1 \%$.

Hasil uji BNT pada tabel 4.6, diketahui bahwa pemberian pupuk NPK Mutiara dengan dosis 50 gram per anakan (N2), merupakan perlakuan 
terbaik untuk meningkatkan pertambahan jumlah pelepah daun anakan Jernang. Hal ini terlihat dengan jelas bahwa $\mathrm{N} 2$ berbeda sangat signifikan dibandingkan dengan N3 (pupuk NPK Mutiara 60 gram per anakan), dengan N1 (pupuk NPK Mutiara 40 gram per anakan) dan dengan N0 (tanpa pupuk NPK Mutiara).

Berdasarkan hasil analisis sidik ragam dan uji BNT seperti yang terlihat pada bagian hasil penelitian, maka hipotesis yang diajukan diterima (tolak Ho dan terima $\mathrm{H}_{1}$ ).

\section{Pembahasan}

\section{Pertambahan Tinggi Anakan Jernang}

Berdasarkan hasil analisis sidik ragam bahwa pemberian pupuk NPK Mutiara memberikan pengaruh sangat signifikan terhadap pertambahan tinggi anakan Jernang pada tanah Podsolik Merah Kuning selama penelitian. Selanjutnya berdasarkan uji BNT diketahui bahwa pemberian pupuk NPK Mutiara dengan dosis 50 gram per anakan $\left(\mathrm{N}_{2}\right)$, merupakan perlakuan yang terbaik untuk meningkatkan pertambahan tinggi anakan Jernang dibandingkan dengan perlakuan lainnya, dengan rerata pertambahan tinggi $7,5 \mathrm{~cm}$. Hal ini mengindikasikan bahwa pemberian pupuk NPK Mutiara dengan dosis tersebut adalah yang terbaik sekaligus paling tepat, karena pada perlakuan tersebut telah terjadi pertumbuhan yang maksimal.

Tanah Podsolik Merah Kuning adalah tanah yang miskin akan unsur hara, sehingga setiap upaya budidaya tanaman di atasnya agar dapat berhasil sesuai harapan, maka harus diberikan hara melalui pemupukan. Tanaman yang dapat tumbuh dengan baik pada tanah ini, berarti kebutuhan haranya telah tercukupi. Hasil penelitian menunjukkan bahwa perlakuan pemberian 50 gram NPK Mutiara per anakan $\left(\mathrm{N}_{2}\right)$ adalah yang terbaik dalam memacu pertumbuhan tinggi anakan Jernang, telah mengindikasikan bahwa jumlah pupuk tersebut telah optimal. Hal ini terlihat dengan jelas, pada pemberian pupuk NPK Mutiara sebanyak 60 gram per anakan $\left(\mathrm{N}_{3}\right)$ justru pertumbuhan tinggi anakan Jernang menjadi lambat bahkan tidak lebih baik dibandingkan dengan perlakuan pemberian pupuk PIPER No. 31 Volume 16 Oktober 2020
NPK Mutiara 40 gram per anakan $\left(\mathrm{N}_{1}\right)$. Hasil penelitian ini dapatlah dinyatakan bahwa, pemberian pupuk NPK Mutiara sebanyak 40 gram per anakan masih belum optimal sehingga pertumbuhan tinggi anakan Jernang belum maksimal, tetapi sebaliknya pemberian sebanyak 60 gram per anakan sudah berlebihan, yang ditunjukkan dengan melambatnya pertumbuhan tinggi anakan dibandingkan dengan pemberian sebanyak 50 gram per anakan $\left(\mathrm{N}_{2}\right)$. Pupuk kimia yang diberikan pada tanaman jika belum mencukupi kebutuhan, maka pertumbuhan tanaman tidak akan optimal sebaliknya jika diberikan dalam jumlah yang berlebihan akan berdampak racun bagi tanaman dan pertumbuhannya pun tidak akan optimal. Pemberian pupuk kimia dengan takaran/dosis yang sesuai, itulah yang akan memberikan respon pertumbuhan yang maksimal bagi tanaman, dan ini ditunjukkan pada pemberian pupuk NPK Mutiara sebanyak 50 gam per anakan $\left(\mathrm{N}_{2}\right)$.

\section{Pertambahan Jumlah Pelepah Daun Anakan Jernang}

Berdasarkan hasil analisis sidik ragam diketahui bahwa pemberian pupuk NPK Mutiara memberikan pengaruh sangat signifikan terhadap pertambahan jumlah daun anakan Jernang pada tanah Podsolik Merah Kuning selama penelitian. Selanjutnya berdasarkan uji BNT diketahui bahwa pemberian pupuk NPK Mutiara dengan dosis 50 gram per anakan $\left(\mathrm{N}_{2}\right)$, merupakan perlakuan yang terbaik untuk meningkatkan pertambahan jumlah daun anakan Jernang dibandingkan dengan perlakuan lainnya, dengan rerata pertambahan jumlah daun sebanyak 4,2 pelepah daun.

Pemberian pupuk NPK Mutiara dengan dosis 50 gram per anakan $\left(\mathrm{N}_{2}\right)$ adalah yang paling optimal dalam memacu pertumbuhan jumlah daun anakan Jernang pada tanah Podsolik Merah Kuning. Pemberian sebanyak 40 gram per anakan $\left(\mathrm{N}_{1}\right)$ masih belum mencukupi sedangkan pemberian sebanyak 60 gram per anakan $\left(\mathrm{N}_{3}\right)$ sudah berlebihan. Pemberian pupuk dengan perlakuan $\mathrm{N}_{1}$ memberikan respon pertumbuhan yang belum optimal sedangkan pemberian pupuk dengan perlakuan $\mathrm{N}_{3}$ justru menghambat lajunya 
Pengaruh Pemberian Pupuk NPK Mutiara Terhadap Pertumbuhan Anakan Jernang (Daemonorops draco) Pada Tanah Podsolik Merah Kuning

pertumbuhan jumlah daun, sehingga pertumbuhan tidak bisa optimal. Pemberian pupuk sangat memegang peranan penting, konsentrasi yang terlalu rendah akan mengakibatkan pertumbuhan dan pertambahan tinggi menjadi lama, sedangkan konsentrasi yang terlalu tinggi akan berakibat racun bagi anakan tanaman, sehingga pertumbuhan dan perkembangannnya menjadi terhambat.

Kesesuaian pupuk, yaitu nitrogen (N) dan fosfor $(\mathrm{P})$ yang tepat adalah hal terbaik untuk merangsang pertumbuhan tanaman, karena unsur fosfor diserap tanaman secara bersamaan dengan nitrogen. Bertambahnya jumlah daun suatu tanaman menunjukkan telah terjadi pertumbuhan. Pertumbuhan yang terjadi pada tanaman merupakan pencerminan dari jumlah dan ukuran protoplasma, serta peningkatan massa sel, sehingga menghasilkan pertambahan jumlah daun. Selain itu pertumbuhan suatu tanaman sangat dipengaruhi ketersediaan karbohidrat dalam tanaman. Proses pertumbuhan tanaman sangat dipengaruhi oleh ketersediaan karbohidrat di dalam tanaman, karena karbohidrat digunakan untuk penunjang proses pertumbuhan dan pendewasaan sel-sel seluruh bagian tanaman.

.Pemberian pupuk NPK Mutiara seperti yang terlihat pada bagian hasil, memberikan pengaruh yang sangat signifikan terhadap pertambahan tinggi dan jumlah daun anakan Jernang. Hal ini menunjukkan bahwa pemberian pupuk NPK Mutiara dengan dosis tersebut mampu memberikan/menyuplai $\mathrm{N}$, $\mathrm{P}$, dan $\mathrm{K}$ serta unsur hara mikro secara optimum untuk pertumbuhan anakan Jernang, karena dari semua unsur hara yang dibutuhkan oleh tanaman, unsur N, P, dan K merupakan unsur - unsur utama yang diperlukan dalam jumlah yang paling banyak.

Pemberian pupuk yang mengandung $\mathrm{N}, \mathrm{P}$, dan $\mathrm{K}$ sangat berguna untuk menambah tinggi tanaman. Pemberian unsur $\mathrm{N}$ pada tahap perkembangan tanaman akan merangsang pertumbuhan dan pertambahan tinggi tanaman, sedangkan adanya unsur $\mathrm{K}$ merupakan sebagai pengimbang pengaruh $\mathrm{N}$ dan $\mathrm{P}$ serta merangsang pertumbuhan akar.

\section{KESIMPULAN}

Berdasarkan hasil penelitian dan pengamatan, maka dapat disimpulkan: (1) Pemberian pupuk NPK Mutiara berpengaruh sangat signifikan terhadap pertambahan tinggi dan pertambahan jumlah daun anakan Jernang pada tanah Podsolik Merah Kuning. (2) Perlakuan pemberian pupuk NPK Mutiara dengan dosis 50 gram per anakan $\left(\mathrm{N}_{2}\right)$ adalah yang terbaik dibandingkan dengan perlakuan lainnya, untuk meningkatkan pertambahan tinggi (rerata $7,5 \mathrm{~cm}$ ) dan pertambahan jumlah pelepah daun anakan Jernang (rerata 4,2).

\section{SARAN}

Perlu dilakukan kajian yang lebih mendalam untuk melihat pengaruh pemberian pupuk NPK Mutiara terhadap pertumbuhan anakan Jernang yaitu dengan cara menambah lamanya waktu penelitian, sehingga didapatkan kesimpulan yang menyeluruh dan utuh.

\section{DAFTAR PUSTAKA}

Buckman, H.O, dan Brady, N.C. 1982. Ilmu Tanah. Diterjemahkan oleh Soegiman. Bharata Karya Aksara. Jakarta

Foth. D.H. 1994. Dasar-Dasar Ilmu Tanah. PT. Erlangga. Jakarta

Hakim, N, dkk, 1986. Dasar-Dasar Ilmu Tanah. Universitas Lampung.

Hanafiah, KA. 2008. Rancangan Percobaan. PT. Raja Grafindo Persada. Jakarta

Hardjowigeno, S. 1987. Ilmu Tanah. Edisi Baru. Akademika Pressindo. Jakarta.

Hyne, K., 1987. Tumbuhan Berguna Indonesia III. Departemen Kehutanan

Lingga, P. 1991. Petunjuk Penggunaan Pupuk. Penebar Swadaya

Salisbury dan Ros. 1992. Fungsi Unsur Hara Makro dan Mikro. PT. Foreverindo Insan Abadi. Jakarta 